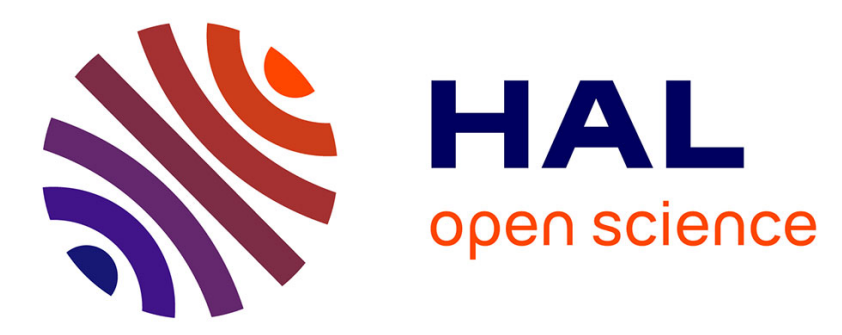

\title{
A conceptual knowledge-link model for supporting dental implant process
}

Anderson Luis Szejka, Osiris Junior Canciglieri, Marcelo Rudek, Hervé

Panetto

\section{To cite this version:}

Anderson Luis Szejka, Osiris Junior Canciglieri, Marcelo Rudek, Hervé Panetto. A conceptual knowledge-link model for supporting dental implant process. Advanced Materials Research, 2014, 949, pp.3424-3429. 10.4028/www.scientific.net/AMR.945-949.3424 . hal-00985485

\section{HAL Id: hal-00985485 https://hal.science/hal-00985485}

Submitted on 30 Apr 2014

HAL is a multi-disciplinary open access archive for the deposit and dissemination of scientific research documents, whether they are published or not. The documents may come from teaching and research institutions in France or abroad, or from public or private research centers.
L'archive ouverte pluridisciplinaire HAL, est destinée au dépôt et à la diffusion de documents scientifiques de niveau recherche, publiés ou non, émanant des établissements d'enseignement et de recherche français ou étrangers, des laboratoires publics ou privés. 


\title{
A Conceptual Knowledge-link model for supporting Dental Implant Process
}

\author{
Anderson Luis Szejka ${ }^{1,2, a}$, Osiris Canciglieri Júnior ${ }^{1, b}$, Marcelo Rudek ${ }^{1, \mathrm{c}}$ and \\ Hervé Panetto ${ }^{2, d}$
}

${ }^{1}$ Graduate Program in Production Engineering and System-PPGEPS, Pontifical Catholic University of Parana-PUCPR, Curitiba, Brazil

${ }^{2}$ CRAN UMR 7039, University of Lorraine, CNRS, Nancy France

aanderson.szejka@pucpr.br, bosiris.canciglieri@pucpr.br, cmarcelo.rudek@pucpr.br, dherve.panetto@univ-lorraine.fr.

Keywords: Knowledge-link. Medical Image Processing. Dental Implant Process. System Engineering. Concurrent Engineering.

\begin{abstract}
Computer aided techniques widely used as diagnostic and surgical procedures tools are scarcely applied in implantology, which continues using visualization of CT images to define the parameters for dental implant process leaving to the dentist discretion the implant determination, since only the images analysis is non-deterministic. Thus, this research proposes the development of a knowledge-link model integrated to a reasoner system to support dental implant process through information modeling. The system presents an interface that interacts with the user and consists of reasoning mechanisms connected by knowledge-links to a base of knowledge that enables information translation, conversion and sharing. The results obtained using the model showed that it is a valuable tool in the decisions making made by the surgeon in the dental implant planning process as it will be based on concrete and measurable data generated by the system through the analysis of the patient's tomographic images and implants data.
\end{abstract}

\section{Introduction}

System Engineering (SE) is an approach for design complex system in multidisciplinary domains [18] allowing the creation of expert systems to support decision process with information, data, image, etc. making the computer solutions safer and more accurate. According to [2] there are different possibilities to design and model complex systems engineering. This research used the knowledge-link approach to convert, share or translate real-data into useful information to support the decision-making. The knowledge-link approach, according to [17] is used to integrate heterogeneous knowledge to overcome barriers that can inhibit the system innovation.

Computed tomography scan (CT scan) is a radiographic technique that consists in the acquisition of images in slices (axial), which it can be interpreted three-dimensional, and storage in DICOM format [12][16]. These images follow the Hounsfield Scale [11], which is standard to medical images and define the value to bone, tissue, nerves, allowed the development of tools that offers support for the decision making process in medical and odontology fields [15]. The image processing within the $3 \mathrm{D}$ reconstruction area through $\mathrm{CT}$ scan provides better visualization of the patient's bone structure [13], overcoming limitations of the conventional dental implant planning, especially in the dental implant planning phase.

In Dental Implant Process, the surgeon has to extract information about dental failure, distance between teeth, nerves localization and other characteristics through visual analysis of tomographic images [3][4] which makes the determining process of suitable dental implant a multivariable and complex process. The researches [1] and [21] point out that the definition phase is extremely important. A right definition reduces the implant rejection risk and premature fatigue and reduces the risk of a facial paralysis by intercepted or sheared nerves. In this context, this research presents a 
knowledge-linked model to support dental implant process through information modeling. The system presents an interface that interacts with the user and consists of reasoning mechanisms connected by knowledge-links to a base of knowledge that enables information translation, conversion and sharing.

\section{Conceptual knowledge-link model to support Dental Implant Process}

Existing computer systems provide the dentist only the process of dental arch three-dimensional virtual reconstruction, as discussed in [4], however they do not offer interactivity or subsidies for decision making to determine the most appropriate implant. To offer interactivity and/or subsidies the conceptual structure should have information enough to support the dental implant process.

In [19][20] was proposed the modeling of information and the manner that they should interact. Thus, the information must be linked to a reasoner system which processes them through reasoning mechanisms provided by the knowledge-link [17] for a simultaneous and automatic analysis of CT images in DICOM format, [15] seeking characteristics that meet the requisites and offer information that support the set of implant selection. A representation of the structure of this conceptual model is shown in Figure 1, where the arrows represent the search for information features and interdependence between one representation and another.

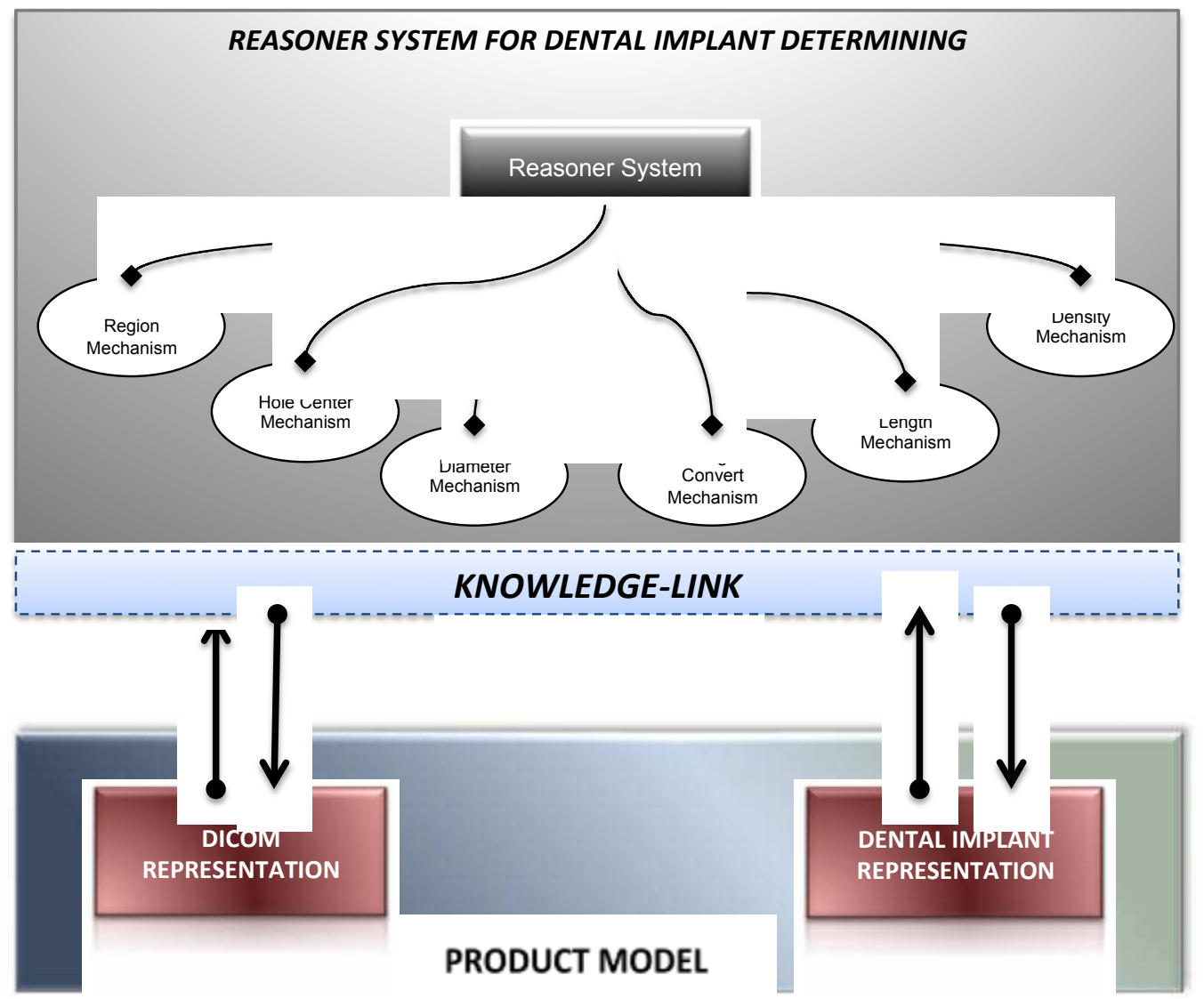

Fig. 1 - Conceptual Model Reasoner System for Dental Implant Determining.

Product Model. In this macro-area is defined the requirements and specifications of information needed to support the reasoner system for dental implant determination. The DICOM Representation contains information extracted directly from the patient's CT scan, divided into 3 structures: the Control Parameters consisting of the patient's physiological information and the scanner information; and the Axial and Transverse Cuts consisting of images that will be used to extract information which will be processed in the identification of the suitable implants. The Dental Implant Representation contains information of dental implants such as classification (type and model), dimension (diameter and length) and characteristics for the appliance of the implant, such as bone density. 
Reasoner System Design for Dental Implant Determining. It is the reasonable mechanisms or inference mechanisms. Each mechanism contains the necessary rules that will be evaluates and logically ordered for the direction to the heuristic process of inference [8]. Through knowledge-link the information contained in the databases of the product model are provided to reasoning mechanisms in matrix patterns allowing their mathematical approach. Figure 2 shows the reasonable mechanisms responsible to translate, convert and share the information contained in the product model and the reasoner knowledge relations with the product model for implant determination.

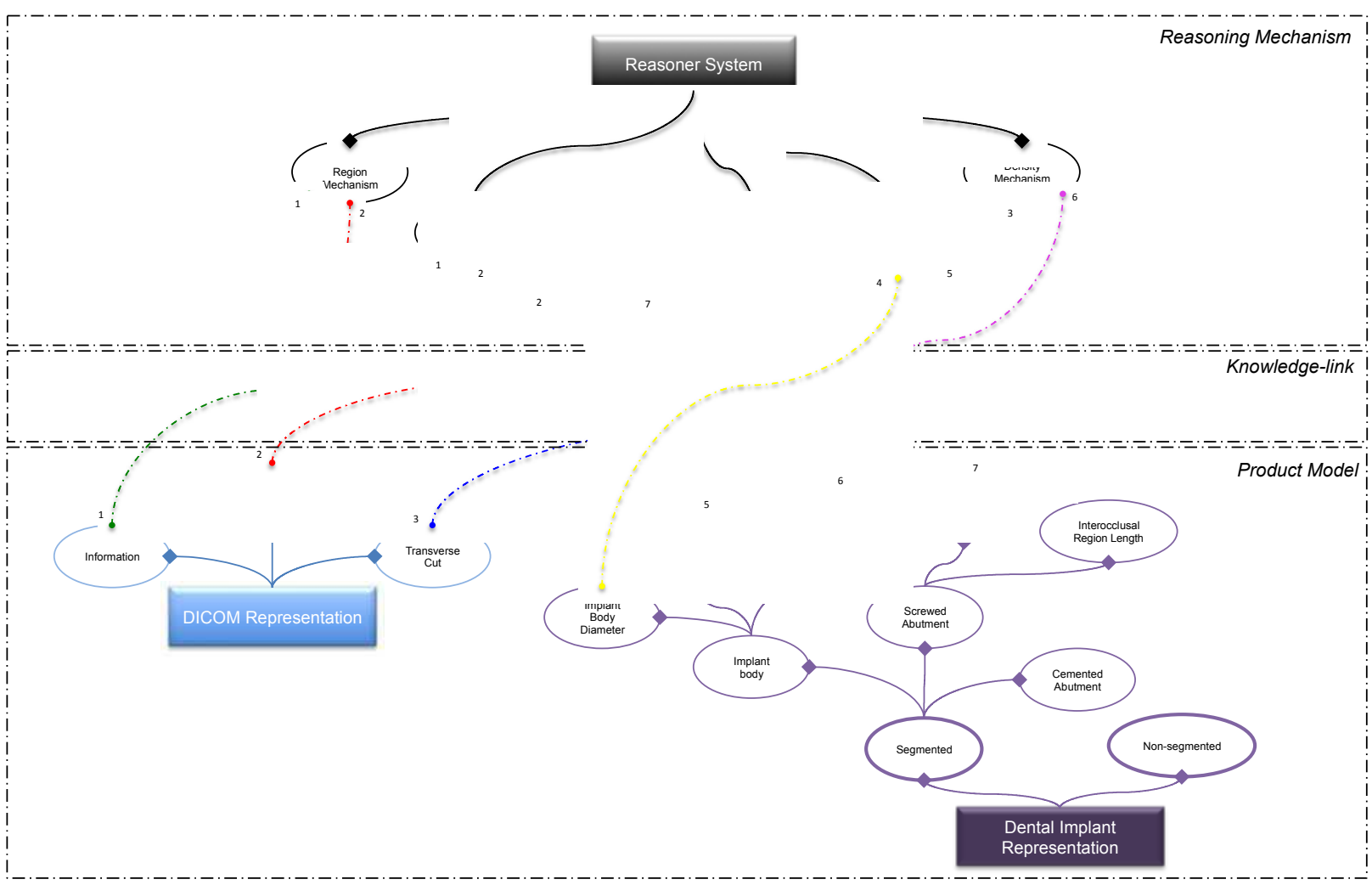

Fig. 2 - Conceptual Knowledge-link model to support Dental Implant Process.

These reasoning mechanisms process the information provided by the Product model representations creating a standardized mathematical knowledge about the problem and propose alternative solutions through cross-checking of the databases information, resulting in a group of set of implants that are suitable to the patient. The knowledge-link proposed in Figure 2, has six reasoner mechanisms to convert, translate and shared information between DICOM representation and Dental Implant representation, which are:

i) Mechanism of region of interest determination - it is used for selecting the region of interest where the implant insertion will occur. The definition of the region of interest is made by the dentist surgeon through observation / analysis of axial images cuts. The region should present the dental failure details of tooth, bone geometry and in the case of partial edentulous, the bordering teeth of the implant's insertion area;

ii) Mechanism of geometric center determination - it is responsible for defining the geometrical center for insertion of the dental implant. This geometric center is obtained by geometric analysis of dental arch bone contour. In the case of partial edentulous in addition to the geometric analysis of the bone contour, it is considered the geometric center of the adjacent teeth;

iii) Diameter Mechanism - responsible for determining the theoretical diameter of the implant, from the distance between the edges of the bones and the insertion center, less $1 \mathrm{~mm}$ of osseointegration process. According to [7], [8] and [9] the implant should be involved with at least $1 \mathrm{~mm}$ of the surface around them. In partial edentulous if the distance from the neighboring to the center is smaller than 
the center and the bone edge, the diameter will be define by the second option as discussed in [25]. From the theoretical diameter the system identifies the real implants contained in the Product Model; iv) Image Convert Mechanism - According to [18], the tomographic image is a volumetric image feasible manipulated in the three dimensions $(\mathrm{X}, \mathrm{Y}, \mathrm{Z})$. The mechanism is responsible for converting the tomographic images in axial cut and from them to transverse cut allowing a deep analysis on the bone (environment $(\mathrm{X}, \mathrm{Z})$ ), identifying nerves and lower bone contours which is not common in the analysis of images in axial cuts (environment (X, Y));

v) Length Mechanism - responsible for determining the maximum theoretical length of the implant respecting the osseointegration and the no obstruction or shearing of the existing nerves. These characteristics define the theoretical length of the implant that will be confronted with the actual information of the implants contained in the Product Model;

vi) Density Mechanism - responsible for analyzing the bone structure of the region of interest, identifying the bone density where the implant will be placed. Based on the classification proposed by [3] and knowing that DICOM follows the Hounsfield scale [14], it is analyzed the bone structure identifying through the histogram method the band that the bone of the region of interest belongs.

From the converted information, shared and translated by these mechanisms the reasoner system compares the information obtained and provides the surgeon with a group of potential dental implants that meet all functional requirements.

\section{Results - Case Study}

In the case study was examined a single dental failure in the mandible area. The reasoner system extracted the information about the limit of the bone edge and nerves in the region, processing them through the mechanisms and provided a detailed image of the failure and insert region as well as data to support the selection (figure 3) such as the dental implant theoretical diameter 3,85mm; dental implant theoretical length $13,5 \mathrm{~mm}$ and bone density D2 type.

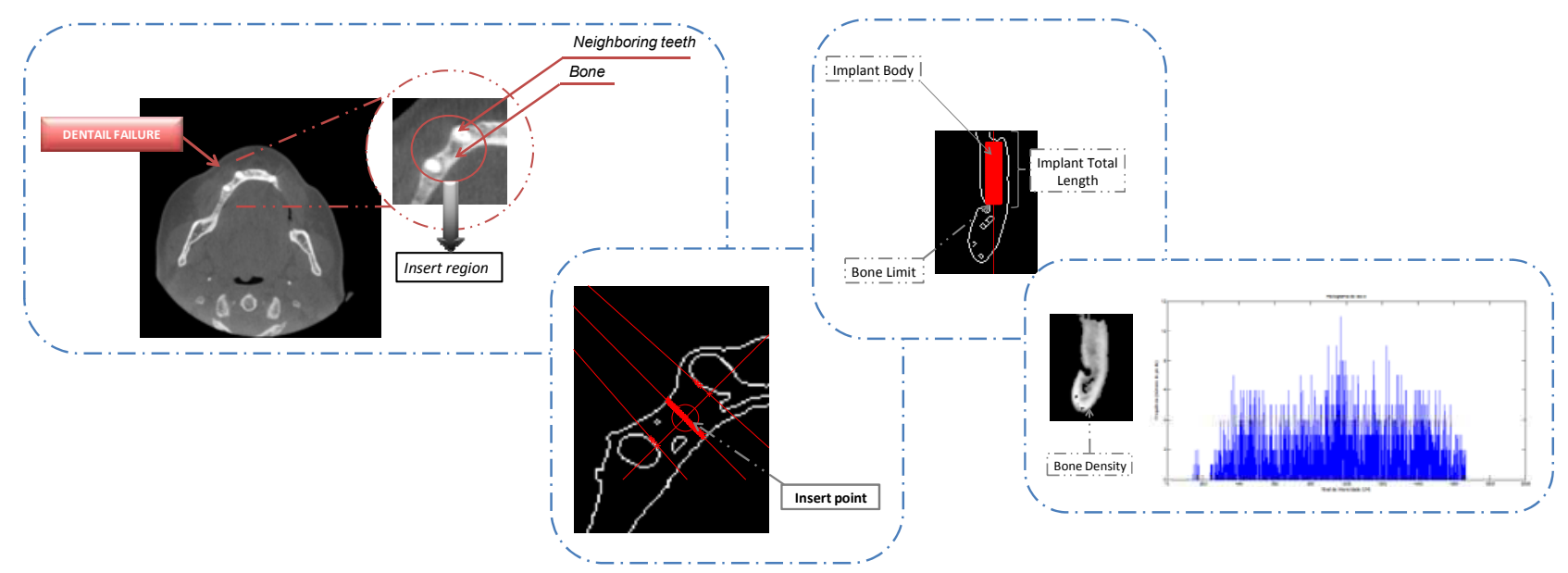

Fig. 3 - Examples of reasoners mechanisms applied to the case study.

With all this gathered information, the system queries the Dental Implant Representation database, within a catalogue with more than 250 different dental implant types, to select the implant sets most suitable for the patient. Then a table with the selected implants is generated. As the information is extracted directly from the patient tomographic image, precision was $0,25 \mathrm{~mm}$. Table 1 shows the generated table for the case study examined in this research. 
Table 1 - Result of the Reasoner System Analysis.

\begin{tabular}{|c|c|c|c|c|c|c|}
\hline Código fabricante & $\begin{array}{c}\text { Tipo do corpo do } \\
\text { implante }\end{array}$ & $\begin{array}{c}\text { Modelo do corpo do } \\
\text { implante }\end{array}$ & Densidade & $\begin{array}{c}\text { Diâmetro do } \\
\text { corpo do } \\
\text { implante }\end{array}$ & $\begin{array}{c}\text { Comrpimento } \\
\text { do corpo do } \\
\text { implante }\end{array}$ & Modelo do pilar do implante \\
\hline 109.616 & CONE MORSE & TITAMAX CM & 2 & 3,5 & 11 & PILAR CM \\
\hline 109.617 & CONE MORSE & TITAMAX CM & 2 & 3,5 & 13 & PILAR CM \\
\hline 109.618 & CONE MORSE & TITAMAX CM & 2 & 3,5 & 15 & PILAR CM \\
\hline 109.609 & CONE MORSE & TITAMAX CM & 2 & 3,75 & 11 & PILAR CM \\
\hline 109.610 & CONE MORSE & TITAMAX CM & 2 & 3,75 & 13 & PILAR CM \\
\hline 109.611 & CONE MORSE & TITAMAX CM & 2 & 3,75 & 15 & PILAR CM \\
\hline 109.633 & CONE MORSE & TITAMAX CM & 2 & 4,0 & 11 & PILAR CM \\
\hline 109.620 & CONE MORSE & TITAMAX CM & 2 & 4,0 & 13 & PILAR CM \\
\hline 109.634 & CONE MORSE & TITAMAX CM & 2 & 4,0 & 15 & PILAR CM \\
\hline 109.464 & HEXAGONO INTERNO & TITAMAX IIPLUS & 2 & 3,75 & 11 & MINI PILAR CONICO II PLUS \\
\hline 109.465 & HEXAGONO INTERNO & TITAMAX IIPLUS & 2 & 3,75 & 13 & MINI PILAR CONICO II PLUS \\
\hline 109.466 & HEXAGONO INTERNO & TITAMAX IIPLUS & 2 & 3,75 & 15 & MINI PILAR CONICO II PLUS \\
\hline
\end{tabular}

The system has selected 12 potential dental implant types suitable for this specific patient, reducing significantly the range of possibilities which allows the dentist a more detailed study before making decision about the more adequate implant and consequently making a better planning of the surgery. Therefore, the conceptual model presents an informational gain as it gives support to the implant process through actual and tangible information, extracted directly from the patient's tomographic image, reducing the range of implant possibilities and improving the implant process and consequently reducing the rejection risks and implant premature failure

\section{Conclusion}

This research presented a conceptual knowledge-link model proposal to support Dental Implant Process through information modeling. The conceptual model was implemented in a computational system that resulted in an expert system which presents an interface that interacts with the user and consists of reasoning mechanisms connected by knowledge-links to a base of knowledge that enables information translation, conversion and sharing.

As the system works actual and tangible information, extracted directly from the patient's tomographic image, it reduces the range of implant possibilities improving the implant process and becoming a valuable tool in the dentist's decisions making. As a result, the rejection risks and implant premature failure is reduced improving the patient's quality of life.

The authors believe that, although the promising results, it is necessary more detailed analysis as well as a research extending the support for other phases of the dental implant process.

\section{Acknowledgements}

The authors are thankful for the financial support provided by Pontifical Catholic University of Paraná - PUCPR.

\section{References}

[1] A. D. Pye, D. E. A. Lockhart, M. P. Dawson, C. A. Murray, A. J. Smith: A review of dental implants and infection, Journal of Hospital infection, 72, 2, (2009), 104-110.

[2] A. Pyster and D.H Olwell (eds): The Guide to the Systems Engineering Body of Knowledge $(S E B o K)$, v. 1.2. Hoboken, NJ: The Trustees of the Stevens Institute of Technology. Accessed 18 mar 2014. Information on www.sebokwiki.org (2013).

[3] C. E. Misch: Implantes Dentários Contemporâneos, 2ed, São Paulo: Santos Livraria Editora, (2000), 210-240. 
[4] C. G. Galanis, M. M. Sfantsikopoulos, P. T. Koidis, N. M. Kafantaris, P. G. Mpikos: Computer methods for automating preoperative dental implant planning: Implant positioning and size assignment, Computer Methods and Programs in Biomedicine, 86, (2006), 30-38.

[5] J. Brink, S. J. Meraw, D. P. Sarment: Influence of implant diameter on surrounding bone, Clinical Oral Implantology Res, 18, 1, (2007), 563-568.

[6] J. H. Lee, V. Frias, K. W. Lee, R. F. Wright: Effect of implant size and shape on implant success rates: A literature review, Journal of Prosthetic Dentistry, 94, 1, (2005), 377-381.

[7] J. M. Mahon, B. K. Norling, R. D. Phoenix: Effect of varying fixture width on stress and strain distribution associated with an implant stack system, Implant Dent, 9, 1, (2000), 310-320.

[8] M. Gruninger, K. Atefi, M. S. Fox: Ontologies to Support Process Integration in Enterprise Engineering, Computational and Mathematical Organization Theory, 6, 4, (2000), 381-394.

[9] M. Rudek, O. Canciglieri Junior, T. Greboge: A PSO Application in Skull Prosthesis Modelling by Superellipse, ELCVIA, Electronic letters on computer vision and image analysis, 12, (2013), $1-12$.

[10] R. Assenciros: Fusão de imagens médicas para aplicação em sistemas de planejamento de tratamento em radioterapia, (2006), 140 f, Tese (Doutorado) - Instituto de pesquisas energéticas nucleares - Universidade de São Paulo, (2006).

[11] R. H. Wiggins, H. C. Davidson, H. R. Harnsberger, J. R. Lauman, P. A. Goede: Image file formats: Past, present, and future, RadioGraphics, 21, 2, (2001), 789-798.

[12] R. N. J. Graham, R. W. Periss, A. F. Scarsbrook: DICOM demystified: A review of digital file formats and their use in radiological practice, Clinical Radiology, 60, 1, (2005), 1133-1140.

[13] S. E. Duff, D. Murray, A. J. Rate, D. M. Richards, N. A. Kumar: Computed tomographic colonography (CTC) performance: one-year clinical follow-up, Clinical Radiology, 61, 11, (2006), 932-936.

[14] S. Jing, F. He, S. Han, X. Cai, H. Liu: A method for topological entity correspondence in replicated collaborative CAD system, Computers in Industry, 60, 1, (2009), 467-475.

[15] S. Jivraj, W. Chee: Rationale for dental implants, British Dental Journal, 200, 12, (2006), 661-665.

[16] T. Li, K. Hu, L. Cheng, Y. Ding, Y. Ding, J. Shao, L. Kong: Optimum selection of the dental implant diameter and length in the posterior mandible with poor bone quality - A 3D finite element analysis, Applied Mathematical Modelling, 35, (2010), 446-456.

[17] T. L. Roberts, W. Leigh, R. L. Purvis, and M. J. Parzinger: Utilizing knowledge links in the implementation of system development methodologies, Information and Software Technology, 43, 11, (2001), 635-640.

[18] INCOSE, INCOSE Systems Engineering Handbook: A Guide for Life Cycle Processes and Activities, The International Council on Systems Engineering, C. Haskins, ed. 3, 2006.

[19] A. L. Szejka, J. Pereira, M. Rudek, O. Canciglieri Jr., Methodological Proposal to Determine a Suitable Implant for a Single Dental Failure through CAD Geometric Modelling, 20th ISPE International Conference on Concurrent Engineering, Amsterdam: IOS Press BV, 1, 35, (2013), $1-11$.

[20] A. L. Szejka, M. Rudek, O. Canciglieri Jr., A Reasoning System to Support the Dental Implant Planning Process, 19th ISPE International Conference on Concurrent Engineering, Trier: Springer, 2, 1, (2013), 909-920. 